\title{
La literacidad crítica en redes sociales virtuales, caso específico de estudiantes de la Facultad de Antropología de la UAEMex
}

\section{Critical literacy in social networks: a case study of students in the Department of Anthropology of the UAEMex}

DOI: https://doi.org/10.32870/dse.v0i23.751

\author{
Claudia Lucía Benhumea Rodríguez* \\ Juan Jesús Velasco Orozco**
}

\begin{abstract}
Resumen
El presente artículo aborda el estudio de la literacidad crítica en una muestra de estudiantes universitarios; el concepto central de la literacidad crítica en el documento se define desde algunas aristas freireanas, y se estudia desde la relación que establecen los estudiantes con las redes sociales virtuales a través la lectura y escritura. Con esta intención, se analizaron las actitudes y percepciones de los estudiantes ante distintos textos que se encuentran de forma cotidiana en las redes sociales. En estudio se eligió trabajar con la red social Facebook, aunque se explora principalmente la forma en que los estudiantes reaccionan a la información y al proceso de toma de conciencia sobre la veracidad y relevancia social de la misma. Los resultados permiten al lector conocer la forma en que se da la literacidad crítica en estos ambientes y las posibles dimensiones a estudiar dentro de esta categoría para el grupo estudiado.
\end{abstract}

Palabras clave: literacidad crítica - red social virtual - Facebook

\begin{abstract}
This article addresses the study of critical literacy in a sample of university students. The central concept of critical literacy in the document is defined after some of Freire' insights and studied through the relationship that students establish with reading and writing on virtual social networks. With this aim, the students' attitudes and perceptions before different texts found on a daily basis on the social network were analyzed. In the document, we chose to work with the social network Facebook, although we mainly explore the way in which students react to information and the process of becoming aware of its veracity and social relevance. The results allow the reader to understand the way in which critical literacy occurs in these environments and the possible dimensions to be studied within this category.
\end{abstract}

Key words: critical literacy - virtual social networks - Facebook.

* Doctora en Educación. Profesora en la Universidad Autónoma del Estado de México. clauluz84@hotmail.com

** Doctor en Antropología Social. Profesor Investigador en la Universidad Autónoma del Estado de México. jivelascoo@uaemex.mx 


\section{La literacidad}

La literacidad se refiere tanto a procesos mentales como a acciones concretas (Barton, Hamilton, 2004; Kalantzis, Cope, 2012); su estudio abarca lo que acontece en el espacio de interacción de las personas, principalmente en torno a las prácticas letradas -llámese lectura y escritura- en lo personal, laboral y social (Kalantzis, Cope, 2012), lo que les confiere un carácter social; por otra parte, se vincula con la transformación de la información a nivel pensamiento, que incluye tanto la representación como la comunicación (Kalantzis, Cope, 2012). La conjunción de los procesos cognitivos y socioculturales permite que en este trabajo se explore la forma en que se manifiesta el uso del pensamiento crítico a través de las prácticas letradas. Cabe mencionar que para Carlino (2005), el término literacidad proviene del inglés y es equivalente al de alfabetización, sin embargo, para este estudio se mantiene dicho vocablo debido a que ya ha sido adoptado en español y existe investigación reconocida bajo este término, particularmente desde los Nuevos Estudios de Literacidad (NEL).

El énfasis en las dimensiones socioculturales de los procesos de lectura y escritura ha permitido comprender que existe más de una literacidad, por ende, se puede hablar de literacidades, que pueden identificarse según el contexto en que se encuentren. Barton y Hamilton (2004) y Carlino y Martínez (2009) destacan esta dimensión social de las literacidades, y Catts y Lau (2008) agregan que estas son un proceso de construcción que se da a lo largo de toda la vida. De acuerdo con Cassany (2007), la diversidad de las literacidades se debe a que hay prácticas vernáculas entre distintos sectores, y estas prácticas se ven a través de la mirada de lo que sucede en el ámbito lingüístico-comunicativo de las comunidades en que se suscita la interacción. La lectura y la escritura se interpretan en los contextos sociales, y su comprensión tiene que ver con su articulación con elementos del mundo real: sus implicaciones, sus relaciones, sus significados, los medios en que se encuentran y los momentos en que se enuncian, etc. Para Barton y Hamilton (2004), incluso estas diferentes literacidades tienen distinta significación.

Entre las múltiples literacidades que existen, en este documento interesa analizar la literacidad crítica, toda vez que conlleva un proceso continuo y complejo que permite la comprensión del mundo mediante el lenguaje oral y escrito, y a través del cual el humano participa en dinámicas personales, sociales, políticas, económicas, etc., que le confieren sentido a su vida desde una postura proactiva. Su participación entonces implica una serie de toma de decisiones que requieren de la capacidad de comprensión, análisis y reflexión -elementos de la crítica- para el ejercicio de su ciudadanía y la transformación de su mundo en los ámbitos descritos.

\section{Las literacidades y los estudiantes universitarios}

Una vez que se ha discutido lo que es la literacidad, es posible ahondar en las literacidades que rodean a los universitarios. De acuerdo con Carlino (2005: 21), una de las quejas más frecuentes del profesorado universitario, al menos para el contexto latinoamericano, es que "los alumnos

Diálopos sobre Educación año 12 | número 23 | julio-diciembre 2021 | ISSN 2007-2171 
no saben escribir. No entienden lo que leen. No leen". Esta queja podría manifestar que las universidades no se perciben como responsables del aprendizaje de los procesos letrados en los estudiantes y que, por lo general, al menos en el diseño de los planes de estudio, esto sea visto como un asunto terminado o bien, implícito, una subhabilidad dentro de otras. No nos detendremos a analizar este factor ya que, como se mencionó, el estado de las literacidades ha cambiado y se reconoce cada vez más su importancia como una habilidad en constante desarrollo. Con base en esto, Carlino indica que es preciso una revisión de las necesidades en torno a las literacidades de las que son partícipes los estudiantes universitarios. En esta revisión aparecen las situaciones que rodean a los universitarios (Ivanic, Weldon, 1994, en Carlino, 2005), la más inmediata, por supuesto, la del contexto académico.

Las literacidades académicas constituyen una de las principales preocupaciones respecto al uso de la lectura y la escritura en estudiantes universitarios, ya que a través de ellas es que pueden "apropiarse de los sistemas conceptual-metodológicos" (Carlino, 2005: 25) de la disciplina en la que están inmersos y, desde luego, incidir en su ámbito laboral. El aprendizaje de las literacidades académicas permite ser partícipe del espacio discursivo de la profesión y de la asunción de elementos de la identidad en el contexto de la comunidad disciplinaria. La investigación y estudio de las literacidades académicas es una constante en el nivel superior y se le ha vinculado con la construcción del conocimiento.

Por otra parte, el avance de la tecnología ha incidido en el surgimiento de las literacidades digitales de las que participan los universitarios. El trabajo de Stuart Selber (2004) plantea la necesidad de ver los procesos de lectura y escritura mediados por el internet y las computadoras desde tres aspectos: lo funcional, lo crítico y lo retórico. Para Selber (2004), leer y escribir tiene que ver con procesos en los que la tecnología tiene lugar como herramienta, como artefacto cultural y como medio hipertextual. Este autor define la literacidad funcional como la capacidad de utilizar una computadora a partir de su propio lenguaje y sus funciones, lo que implica conocer sus posibilidades de uso en los ámbitos cotidianos. Como literacidad crítica entiende la capacidad de comprender las computadoras como un medio para extender la cultura y todas las actividades humanas, por lo que su uso tiene que ver con sus posibilidades para incidir en el mundo social. En cuanto a la literacidad retórica, el autor refiere la integración de las capacidades anteriores, para el "diseño y evaluación de las interfaces computacionales" (Selber, 2004: 145). Como se puede vislumbrar hasta ahora, los universitarios se desenvuelven en las prácticas letradas de formas particulares que incluyen lo académico y lo digital, y en el trabajo de Selber se ha encontrado la necesidad de plantear un componente crítico en el uso de lo digital.

Aunado a lo anterior, de acuerdo con Rovira (2016), los procesos comunicativos en la actualidad permiten que cualquier miembro de la sociedad pueda convertirse en emisor y a la vez en receptor, sin importar a qué sector social pertenezca. Los discursos hegemónicos de las instituciones del Estado y de las mismas empresas de comunicación han dejado de tener 
la importancia que tenían, dando lugar a los discursos "contrapúblicos" (Rovira, 2016: 90). Esto refuerza la idea anterior de educar a los estudiantes, incluyendo a los universitarios, para utilizar las prácticas letradas de forma crítica. La proactividad de los grupos juveniles en las redes sociales virtuales deja de manifiesto la necesidad de conocer cómo se integran en los procesos sociales y políticos del entorno en el que se encuentran.

\section{La literacidad crítica y las redes sociales virtuales}

Además de haber definido los ámbitos de uso de las literacidades en los universitarios, es necesario distinguir las razones por las que se percibe que la literacidad crítica es relevante en la actualidad. La computadora es un artefacto cultural en el que se despliega un número importante de interacciones en los ámbitos personal, laboral, social, político, económico de los individuos, que los convierte en una comunidad con referentes culturales y lingüísticos propios; por ello, es indispensable dotar a los individuos de capacidades que les permitan asumir decisiones respecto a las prácticas letradas que utilizan en los medios digitales. Dicho lo anterior, es posible anticipar la razón por la que en el documento se analizan los roles, nociones y principios de los procesos de la comprensión, no solo lectora sino del mundo, a través del lenguaje, principalmente en sus formas escritas.

Desde este ángulo, la crítica se convierte en uno de los pilares de la educación ya que a través de ella se percibe la posibilidad de formar personas que puedan afrontar la complejidad e incertidumbre ante la información que circula en los medios utilizados en la sociedad actual. El análisis de las formas en que se dan los procesos de comprensión de la lectura en entornos que integran las esferas de acción de los jóvenes, da cuenta de las necesidades en su formación y de los retos que afronta la universidad en este ámbito. En una revisión general de reportes sobre el uso del internet y redes sociales virtuales en México, se encontró que los grupos que mayoritariamente usan internet son aquellos que se encuentran en el rango de edad entre los 18 y 24 años y que es más probable que lo usen los estudiantes de nivel superior, en relación con cualquier otro sector educativo del país (IFT, 2019; IAB México, 2019; INEGI, 2019).

Esas son algunas de las razones por la que interesa analizar la literacidad crítica en el artículo, la cual, con base en Yagelski (2000) y Freire (2006), los autores de este artículo hemos definido como los procesos y acciones que tienen lugar en el ámbito de la interacción y la comunicación, a través de los cuales los estudiantes estructuran, autodeterminan y viven su mundo en función de la comprensión de los procesos sociales detrás de la lectura y escritura en los distintos ámbitos en los que sucede. La lectura, en este sentido, se ve como un proceso de reconocimiento del mundo que nos rodea, para comprenderlo, de comprender sus fenómenos y de comprenderse a uno mismo como persona, en una temporalidad y una sociedad específicas en las que se cobra conciencia a través de la relación que existe con uno mismo, con los otros y con el entorno; por su parte, la escritura se ve como un proceso de participación en un proyecto social, en el que el

Diálopos sobre Educación año 12 | número 23 | julio-diciembre 2021 | ISSN 2007-2171 
sujeto ejerce democráticamente su derecho a expresarse desde su identidad, su creatividad y su sentido de comunidad, en ámbitos que trascienden el plano real y se trasladan al plano digital. Lo anterior lleva a cuestionar si es necesario repensar en estos procesos de uso y aprendizaje de la lectura y escritura en la universidad; en este artículo se analiza prioritariamente la primera.

Como se ve, el artículo no desestima el valor de la alfabetización funcional, al contrario, se sitúa en un plano en el que esta es parte de un continuum en el que los ámbitos de uso del lenguaje dan lugar a su aprendizaje. Por otra parte, en las definiciones que se han propuesto para este artículo, es posible encontrar categorías para acercarse a conocer cómo se da esta literacidad crítica en los estudiantes de licenciatura. Como se ha dicho, la literacidad crítica se entiende como proceso y acción, por lo que es necesario conocer cómo actúan los estudiantes en los ámbitos comunicativos donde se da una interacción constante de lo que se lee y escribe en el mundo real y, habiendo visto que los estudiantes utilizan el internet con gran frecuencia, resulta un medio idóneo. Un espacio del internet donde los estudiantes pueden expresar su identidad son las redes sociales virtuales. De acuerdo con Beltrán (2017: 113), dentro de las redes sociales virtuales se "despliegan recursos del lenguaje [...] y de la cultura" que dan lugar a interacciones multimodales en las que se ejerce el poder y, en este sentido, la literacidad crítica cobra un papel fundamental, sobre todo si se mira su rol para lidiar con la complejidad de la información que tiene lugar en este espacio virtual, cuestionando su veracidad y el impacto de su interpretación en la realidad. De acuerdo con los documentos consultados, el uso de la red social virtual Facebook ha crecido en todos los sectores de la población mexicana, principalmente en la del rango de los 18 a 24 años, lo que implica que los estudiantes universitarios son partícipes de estas redes de manera constante.

En la revisión de documentos sobre el estudio de temas similares se encontró el trabajo de Cassany y Castellá (2010), "Aproximación a la literacidad crítica", donde se discute de forma general el término criticidad y traza algunas de las raíces del concepto en la teoría crítica, la pedagogía crítica, el posestructuralismo, el análisis crítico del discurso y los nuevos estudios de literacidad. Otro documento consultado es el trabajo de Tejada y Vargas (2016), "Hacia una integración de la literacidad critica, la literacidad funcional y la literacidad cultural", donde dice que, efectivamente, la literacidad crítica debe ser una categoría diferente a la funcional y a otras literacidades, porque por lo general el discurso escrito fuera de los ámbitos académicos carece de neutralidad; esto, de alguna forma refuerza la importancia de comprender este tipo de literacidad, sobre todo en el sector que se ha descrito. Por otra parte, se encontró el trabajo de Ávila (2016), "Literacidad digital a través del currículum universitario: cursos, recursos y prácticas", donde se analizan las formas en que las universidades pueden potenciar las literacidades digitales de manera intencionada con base en necesidades particulares; por otra parte, Vargas (2015), presentó el trabajo “Literacidad crítica y literacidades digitales: ¿una relación necesaria? (Una aproximación a un marco teórico para la lectura crítica)", que justamente aborda una de las categorías centrales 
de este artículo, en el entorno que también se ha elegido; más tarde, en 2018, el mismo autor realizó el trabajo "Redes sociales, prácticas letradas e identidad(es): el caso de Facebook. Una aproximación al estado del arte", donde describe y caracteriza las actividades y prácticas letradas de un grupo seleccionado a través de esta red social.

Lo anterior permite ver que existen ya algunos trabajos incursionando en la convergencia entre las literacidades críticas y digitales, y aunque por ahora no las separamos en el artículo, vislumbramos que existe una relación entre lo digital y el ámbito de la crítica. Cuando se habla de la crítica en este documento, además de posicionarse entre los Nuevos Estudios de Literacidades, se retoma el concepto de Freire (2006) sobre la crítica, que sirve de base a la definición propuesta, y también permite encontrar formas de analizar esta literacidad a través de lo que se ha estudiado en esta categoría; así, para la construcción del instrumento se tomó como base la revisión de textos que desglosan la crítica.

\section{Estudiar la literacidad crítica}

Hasta ahora se han referido aquí algunas investigaciones que estudian la literacidad crítica: la de Cassany (2014), la de Vargas (2015; 2018), la de Tejada y Vargas (2016) y la de Ávila (2016). Para Cassany, la crítica consiste en una serie de procesos que van desde "situar el texto en el contexto sociocultural", hasta "calcular los efectos que causa un discurso en la comunidad" (Cassany, 2014: 92). Por su parte, Tejada manifiesta que todo discurso es parte de una serie de relaciones temporales y culturales indisociables, por eso todo se entiende en un marco cultural que no es neutro, y está integrado por fases descriptivas, interpretativas personales, de análisis crítico y de acción creativa, asociadas con el ejercicio de la democracia. Para Vargas (2015), la crítica tiene que ver inicialmente con el análisis del rigor y la veracidad.

De los textos revisados, solo Cassany (2014) propone un modelo completo para evaluar la criticidad, y en su trabajo con Castellá (2010) deja entrever algunas de las posibles teorías que pueden servir de base para el análisis. De estas, en el presente documento se retoma un modelo vinculado con la definición de crítica de Freire (2006), que tiene como base una arista centrada en el pensamiento $y$, como se ha dicho, las literacidades se caracterizan por tener ámbitos de cognición articulada con el plano sociocultural. En un primer documento revisado, Flecha (2004) visualiza algunos ejes en la definición de Freire, entre los que destacan el diálogo igualitario, la inteligencia cultural, la transformación, la creación de sentido, la igualdad de las diferencias y la solidaridad. Si bien el trabajo de Flecha no se relaciona con las literacidades, sí lo hace con una propuesta de educación democrática y, en este sentido, guarda una relación con el aprendizaje implícito que conllevan las literacidades. El segundo documento utilizado es el trabajo de Santaella (2014), que define las características centrales de la pedagogía crítica tales como: colectividad, horizontalidad, empoderamiento, discurso democrático, construcción propia del conocimiento, transformación de la realidad, acción participativa, reflexión crítica, y 
autocrítica. El trabajo de estos dos autores se centra en la pedagogía crítica, y siendo esta una fuente de los estudios de literacidad (Cassany, 2007, 2014), aquí se retomaron estos ejes como parte de un modelo observable para conocer la literacidad crítica en estudiantes universitarios.

Con esto en mente, la literacidad crítica implica la comprensión del mundo y el ejercicio de la lectura y la escritura a través de un proceso dialógico con los otros, en el que la persona se reconoce conscientemente desde su historia y desde el sentido de su vida, y se identifica como un ser empoderado cuyo objetivo es contribuir a la transformación social en la búsqueda de la horizontalidad, es decir, que no intenta dominar sino comprender los propósitos en el uso de la información, mediante el ejercicio democrático, con respeto y empatía hacia los demás y en un contante proceso autocrítico. En el estudio que nos ocupa se da cuenta de la realización de un ejercicio en el que se busca conocer cómo se da parte de este proceso a través de la participación los estudiantes universitarios en ámbitos de lectura y escritura en redes sociales virtuales.

Los elementos aportados por Flecha (2004) y Santaella (2014) permiten acotar siete dimensiones que asociamos a la literacidad crítica; para cada una de ellas se propone una definición que permite su observación y análisis dentro de la literacidad crítica; a este respecto, se aclara al lector que este artículo se deriva de un trabajo de tesis doctoral, titulado "Propuesta de un modelo de literacidades para potenciar el desarrollo humano en la Universidad Autónoma del Estado de México", y parte de lo que se define aquí se desglosa de forma más amplia en uno de los capítulos de la tesis.

1. Diálogo horizontal y democrático (DHD): Comunicación con otros sin buscar ningún tipo de dominio, ni de la persona a otros ni de otros a la persona. Comprensión del derecho y responsabilidad de la expresión con la conciencia de sus consecuencias.

2. Pensamiento colectivo (PC): Comprensión de la valía de las personas en lo individual y colectivo, así como con el medio, por lo que se llevan a cabo comportamientos respetuosos a estas interrelaciones.

3. Empoderamiento (E): Comprensión de la persona como un ser digno, con derecho a elegir la vida que valora y con la capacidad y el derecho de transformar su entorno desde una perspectiva de bien común. Reconocimiento de la propia capacidad para crear y expresarse con la intención de convivir de manera respetuosa con otros y el entorno individual y colectivo.

4. Construcción propia del conocimiento (CPC): Responsabilidad acerca de la adquisición del propio conocimiento de manera historizada, es decir, comprender el pasado personal y colectivo, la situación presente y la prospectiva. Comprensión de las propias formas de aprender.

5. Acción participativa (AP): Reconocimiento de la propia proactividad asertiva para ejercer su acción dentro de distintos ámbitos locales y globales para transformar su realidad. 
6. Solidaridad (S): Comprensión de la necesidad de aportar a la colectividad desde la alteridad y empatía.

7. Autocrítica (A): Reconocimiento de la necesidad de examinar los procesos individuales de manera dialéctica. Capacidad para sobreponerse a circunstancias desfavorable desde el análisis de la interrelación con la propia vida.

Las definiciones anteriores permiten cuestionar cómo es que se dan las literacidades críticas, y cómo las podríamos comprender a través de un instrumento. Los cuestionamientos inciden en la comprensión de sí mismo del sujeto, sus procesos, la información y la forma en que esta afecta a la sociedad.

\section{Método}

Como se ha visto, este documento busca conocer cómo se da la literacidad crítica, con énfasis en el proceso lector, en estudiantes universitarios cuando utilizan la red social Facebook. Para analizar lo anterior y dada la naturaleza de la lengua, este trabajo tuvo un carácter interpretativo. De acuerdo con Dilthey (en Martínez, 2004: 57), el proceso de interpretación tiene que ver con un "movimiento del pensamiento que va del todo a las partes y de las partes al todo", alejándose de los apriorismos del investigador. En este sentido, se usó un instrumento ${ }^{1}$ que integra las dimensiones mencionadas, descritas a manera de reactivos de opción múltiple y abiertos, por lo que hay algunos detalles estadísticos, pero la mayoría de los análisis interpretativos tienen que ver con reactivos que simulan elementos encontrados en la red social virtual seleccionada. Para lo anterior, se aplicó un cuestionario en algunos grupos de la Facultad de Antropología de la Universidad Autónoma del Estado de México (UAEMex) por varias razones, la más importante: que en un análisis realizado por Benhumea, Arriaga y Velasco (2020) sobre las capacidades que se promueven en los planes de estudio, se encontró que en la Licenciatura en Antropología Social se desarrollan algunas capacidades, entre las que destaca de forma reiterada el pensamiento crítico.

La selección de los estudiantes tuvo que ver con una muestra no probabilística de 44 estudiantes que cursaban el tercero y quinto semestre de la licenciatura, principalmente. Los estudiantes recibieron el cuestionario al iniciar su segunda clase del día y tuvieron cerca de una hora para contestarlo, aunque la mayoría terminó en los primeros 20 minutos. De acuerdo con los datos demográficos de los estudiantes, la edad de los involucrados oscila entre 20 y 24 años, y se observó una predominancia de mujeres en los grupos.

En las secciones previas se ha definido la literacidad crítica como una categoría que integra la lectura y la escritura, sin embargo, a pesar de que se perciben como procesos indisociables,

1 El instrumento se puede consultar en el siguiente vínculo: https://forms.gle/aEKrKSEZQ2qCcFGh6 Para conocerlo hay que completarlo ya que las secciones que se utilizaron como obligatorias se mantienen en el cuestionario de muestra.

Diálopos sobre Educación 
al haber elegido el análisis de una red social y utilizar cuestionarios para conocer el actuar de los estudiantes, preponderantemente se percibió el proceso de la lectura. La construcción del cuestionario tuvo en cuenta los posibles ámbitos de lectura de los estudiantes en las redes sociales virtuales $y$, tomando como base el perfil de la carrera, se buscó que los textos tocaran los ámbitos personal, laboral, profesional y social. Para lo anterior, se utilizaron preguntas generales y se integraron textos cortos asociados con noticias importantes en el momento de la aplicación. Desde el inicio, la intención fue utilizar noticias muy conocidas que les permitieran construir preferentemente narrativas híbridas a través de lo que ellos ven en distintos canales formales e informales, tales como internet, redes sociales virtuales, televisión, radio, pláticas con otras personas y en la escuela, con el propósito de tener información que diera pie a utilizar la escritura a través de su conocimiento previo sobre el tema.

El instrumento contiene 28 reactivos asociados con elementos cualitativos y cuantitativos, mediante respuestas de opción múltiple, selección múltiple y escalas de valoración, todos con opción a comentarios abiertos. El documento se divide en tres secciones que abordan los siguientes ámbitos: la primera, con 24 reactivos, aborda los hábitos de los participantes en cuanto a los medios que utilizan, horas que pasan en los entornos digitales, frecuencia de uso, tipo de información que consultan, redes sociales virtuales que usan, frecuencia para compartir información, tendencias de información, tipo de publicaciones, impacto de las publicaciones y peticiones que leen, comentan, comparten y a las que reaccionan. De igual forma, se ahondó acerca de hábitos de análisis de la información respecto a su confiabilidad y veracidad, y el cuidado de su seguridad mediante la configuración de las plataformas. En la misma sección se cuestionó sobre la forma en que leían la información sobre noticias asociadas a acontecimientos importantes en el ámbito social, las emociones que expresaban y si la información consultada los llevaba a movilizarse de alguna manera, ya sea a través de la discusión de contenidos, acudir a marchas, realizar campañas, etc. De igual forma, se interrogó sobre los tipos de interacción con otras personas a través de las redes y sobre su lugar en el proceso comunicativo.

Los 24 reactivos que constituyen la primera sección del cuestionario tienen que ver con las categorías definidas anteriormente. Los reactivos se asocian a una categoría en particular en algunos casos, y en otros reflejan varias de las categorías, según el tipo de información que se cuestiona. En la siguiente tabla se muestra la relación que guardan los reactivos del instrumento con las categorías de la literacidad crítica. 
Tabla 1. Reactivos de la primera sección, relación con los elementos

\begin{tabular}{ll}
\hline $\begin{array}{c}\text { Elemento del pensamiento crítico con base en } \\
\text { la perspectiva de Freire (Flecha, 2005; Santaella, 2014) }\end{array}$ & \multicolumn{1}{c}{ Sección 1 } \\
\hline Diálogo horizontal y democrático (DHD) & $10,11,18,23$ \\
\hline Pensamiento colectivo (PC) & 17 \\
\hline Empoderamiento (E) & 5,19 \\
\hline Construcción propia del conocimiento (CPC) & $1,2,3,4,12,16,21$ \\
\hline Acción participativa (AP) & $7,8,22,23$ \\
\hline Creación de sentido (CS) & 6,9 \\
\hline Solidaridad (S) & 15 \\
\hline Autocrítica (A) & $13,14,24$ \\
\hline
\end{tabular}

Fuente: elaboración propia.

En la segunda sección se mantuvieron algunas de las preguntas anteriores, agrupadas en tres noticias seleccionadas. Las noticias se relacionaban con asuntos que suelen aparecer en los encabezados de las noticias del país, y con el entorno social, político y económico que afecta en las esferas de la vida familiar y de la comunidad. Se utilizaron capturas de pantalla, dando información similar a la que aparece en la pantalla principal de noticias de Facebook, las preguntas nuevamente fueron de opción múltiple (4 por cada noticia), pero en todas había la opción de colocar comentarios abiertos. En algunos casos las noticias carecían de fecha, autor, lugar, etc., y en particular, la última presentaba información de hace varios años. La intención era evaluar la lectura y reacción de los estudiantes ante las noticias (todas sensibles) y corroborar si ellos analizan la calidad de contenidos leídos.

El primer reactivo que seguía la noticia, presentaba opciones para conocer la actitud, utilizando los íconos de Facebook (me gusta, me encanta, me divierte, me sorprende, me entristece, me enoja), seguida de opciones asociadas a compartir la noticia, leer más sobre ella, revisar su veracidad, comentar la noticia en la red social (dando espacio para el comentario), y seguir deslizando la pantalla sin abrir la noticia. En el caso de que los estudiantes la conocieran previamente, se les preguntaba cómo se habían enterado de ella y cuál sería su reacción en términos de movilización social: acudir a marchas o plantones, comunicarse con representantes de gobierno, distribuir folletos sobre el tema, escribir cartas a editores de periódicos, iniciar o firmar peticiones, publicar estados en redes sociales virtuales, realizar campañas de conciencia sobre el tema, unirse a tendencias a través del hashtag; y finalmente, se les cuestionaba en cada caso sobre la emoción que experimentaban, en un rango de 28 emociones (aburrimiento, angustia, ansia, asombro, compasión, curiosidad, decepción, trabajo, enojo, empatía, euforia, frustración, hastío, horror, indiferencia, indignación, ira, miedo, nostalgia, pesimismo, plenitud, repudio, seguridad, solidaridad, vacío existencial, valentía, vergüenza). Se estableció un espectro de varie- 
dad e intensidad en las emociones. La relación que guardan los reactivos en cada noticia con las dimensiones elegidas, son las siguientes:

Tabla 2. Reactivos de la sección 2 y su relación con las categorías de la literacidad crítica

\begin{tabular}{ll}
\hline \multicolumn{1}{c}{ Preguntas en el instrumento } & \multicolumn{1}{c}{ Categorías } \\
\hline $\begin{array}{l}\text { ¿Cuáles serían tus reacciones ante la noticia? Coloca el } \\
\text { orden de aquellas que seguirías. }\end{array}$ & E (Empoderamiento) \\
\hline ¿Cuál es tu reacción posterior ante noticias como la & AP (Acción participativa) \\
anterior? & \\
\hline ¿Qué emociones experimentas con noticias similares? & S (Solidaridad) \\
\hline
\end{tabular}

Fuente: elaboración propia.

Para el caso de la sección que permite el análisis interpretativo, la primera noticia que los estudiantes leyeron era real y publicada por un medio oficial, aunque sin establecer la fecha. Al igual que en la red social, se mostraron las reacciones de otros internautas, permitiendo visualizar las emociones mayoritarias que se habían generado a través de la noticia. El caso apareció por primera vez en 2018 y se le dio seguimiento en medios nacionales e internacionales de manera consecutiva, debido a que fue un caso que quedó sin resolver (al menos de manera pública) respecto a lo sucedido en realidad entre las autoridades y la persona de la imagen (un estudiante). En julio de 2019 se dieron a conocer varias noticias donde se entrevistaba a la persona para conocer la verdad del caso, uno de los pocos cuyas incógnitas se pudieron resolver, una vez que la persona logró recordar lo sucedido. El título de la noticia "Marco Antonio Sánchez Flores, ecos de una desaparición forzada", contenía un enunciado en pasado, que dejaba ver que el texto era una narración con elementos descriptivos. Para el segundo análisis se seleccionó una noticia real, reciente y parecida a muchas otras, donde se da seguimiento a asaltantes, ladrones y asesinos. La noticia abordaba un encabezado con un juego de palabras que enfatizaba la violencia y el uso de lenguaje coloquial. En la imagen predominaba un elemento relacionado con el juego de palabras, dejaba ver un aspecto deshumanizante y tenía problemas de puntuación. El titular tenía el aspecto sensacionalista: “Víctima de asesino serial 'El Juguetero' robó camioneta y amenazó con un arma a dos mujeres". No se colocó fecha, pero se percibe como algo reciente al aparecer la impresión de pantalla 10 horas atrás. Finalmente, para la tercera sección, se seleccionó una noticia cotidiana; sin embargo, a diferencia de las noticias anteriores, se seleccionó el texto de una agencia de noticias desconocida. El título no lucía sensacionalista “EI aumento de la gasolina es temporal, Secretaría de Economía", sin embargo, aquí la fecha indicaba 5 de marzo. Ninguno de los estudiantes comentó algo respecto a la fecha o sobre la empresa que publicaba la noticia. 
Imagen 1. Ejemplo del reactivo 25 en el cuestionario

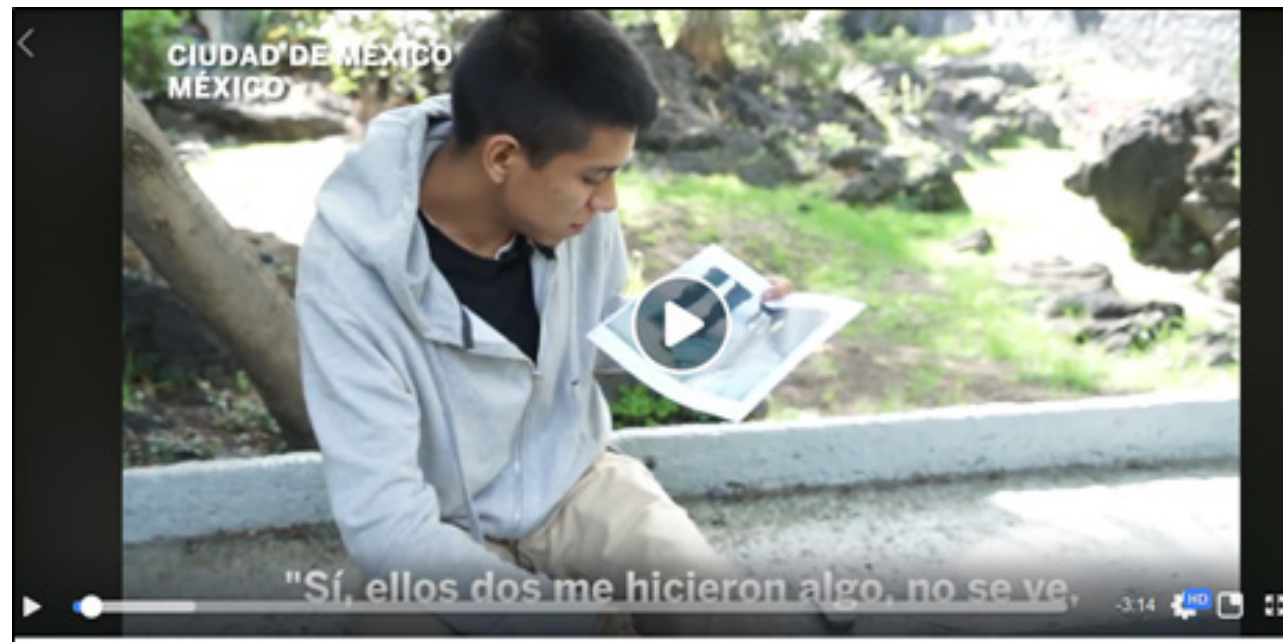

Marco Antonio Sánchez Flores, ecos de una desaparición forzada

E el pais América

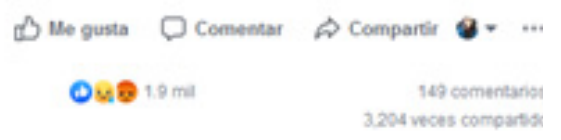

Fuente: Impresión de pantalla de una publicación de El País América, en Facebook.

En la tercera sección se indicaba a los estudiantes que verían una serie de imágenes aparecidas en redes sociales virtuales. Se buscó que las imágenes fueran lo más claras posible y que emularan el 'feed' que aparece en la sección de noticias de un internauta en Facebook. La intención de lo anterior fue que los participantes siguieran el proceso de lectura que usan mientras deslizan la pantalla del teléfono o computadora al estar conectados a la red social. Se presentaron 12 imágenes, cada una tenía que ver con un aspecto con el que los estudiantes pudieran relacionarse. En los reactivos se les daba la opción de expresar su preferencia a través de los íconos propios de Facebook, y se les preguntaba si la compartirían y por qué. Cabe destacar que en este caso no se hicieron obligatorias las respuestas dentro del formulario, justamente para saber si los estudiantes se detendrían a leer la información y saber a qué tipo de información reaccionaban en la cotidianeidad. Sumado a esta intención, se quería observar si se llevaba a cabo algún proceso reflexivo respecto a la veracidad de la información en internet y respecto a su análisis acerca de la utilidad en las esferas de lo personal, lo social, lo laboral y lo académico.

A continuación, se listan las características de las 12 imágenes de esta sección, que además se contabilizaron como un solo reactivo. 
Tabla 3. Reactivos de la sección 3

\begin{tabular}{|c|c|}
\hline No. & Características de la imagen \\
\hline 1 & $\begin{array}{l}\text { Infografía sobre los elementos de un documento académico en el ámbito personal (al ser estu- } \\
\text { diantes) y para otros miembros en su círculo social inmediato. }\end{array}$ \\
\hline 2 & $\begin{array}{l}\text { Noticia expresada a manera de texto informativo objetivo al colocar como referencia a la cien- } \\
\text { cia. La fuente que se dejó de forma intencionada, parecía tener un juego de palabras asociadas } \\
\text { a información cómica. }\end{array}$ \\
\hline 3 & $\begin{array}{l}\text { Información con tintes religiosos, con información que expresa dudas por el uso de comillas, } \\
\text { puntos suspensivos al final, y al enunciar un hecho que de manera científica no se reconoce como } \\
\text { objetivo. }\end{array}$ \\
\hline 4 & $\begin{array}{l}\text { Texto corto, donde se hace una denuncia social sobre un asunto de género internacional, en el } \\
\text { que se invita al lector a compartir para evitar complicidad. La información no cuenta con ninguna } \\
\text { evidencia de donde se ha tomado. }\end{array}$ \\
\hline 5 & $\begin{array}{l}\text { Imagen instructiva alusiva a un problema de salud. La imagen describe una situación de riesgo } \\
\text { que cualquiera puede afrontar, carece de fuentes y fue tendencia en redes sociales virtuales al } \\
\text { momento de realizar el cuestionario. Facebook desmintió la noticia enviando mensajes a to- } \\
\text { das las personas que la hubieran compartido, indicando que la información carecía de evidencia } \\
\text { científica. }\end{array}$ \\
\hline 6 & $\begin{array}{l}\text { Imagen humorística alusiva a la situación que enfrentan estudiantes frente a un computador, al } \\
\text { optar por actividades recreativas en lugar de realizar actividades académicas. }\end{array}$ \\
\hline 7 & $\begin{array}{l}\text { Imagen alusiva a un científico reconocido de la actualidad. La imagen indica ser la impresión de } \\
\text { pantalla de un video, al mostrar la leyenda de YouTube. El video parece ser una conferencia del } \\
\text { autor sobre el progreso. Parte del texto aparecía en inglés. }\end{array}$ \\
\hline 8 & La imagen contiene un pensamiento tipo poema romántico. \\
\hline 9 & $\begin{array}{l}\text { La imagen consiste en una invitación para colaborar con un museo. No se dan detalles de la } \\
\text { localización del museo, pero el cartel informativo da datos sobre la página oficial del museo. La } \\
\text { información es de tipo cultural informativo. }\end{array}$ \\
\hline 10 & $\begin{array}{l}\text { La imagen es una noticia real, publicada por una agencia de noticias reconocida, y que en el } \\
\text { momento de la aplicación del cuestionario tenía que ver con un asunto altamente tratado en los } \\
\text { medios de comunicación. El documento parecía ser una editorial o artículo de opinión. }\end{array}$ \\
\hline 11 & $\begin{array}{l}\text { La imagen corresponde a un proceso. La fuente de la página tiene que ver con recetas y tutoria- } \\
\text { les, en este caso, para cocinar algo. Los íconos utilizados denotan la intención persuasiva. }\end{array}$ \\
\hline 12 & $\begin{array}{l}\text { En la imagen aparece un texto informativo sobre una noticia popular en la comunidad de los } \\
\text { estudiantes que contestaron el cuestionario, la noticia contenía elementos informativos y per- } \\
\text { suasivos con suficientes datos de contacto y fecha. }\end{array}$ \\
\hline
\end{tabular}

Fuente: elaboración propia. 
Imagen 2. Imágenes usadas en los reactivos de la sección 3

1

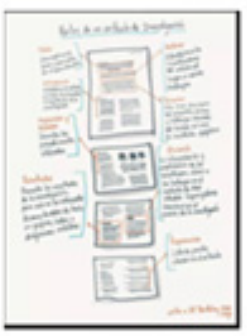

5

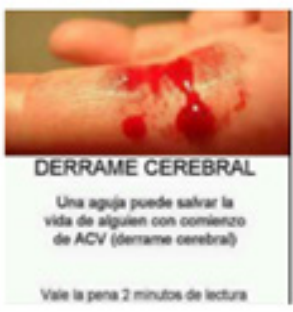

9

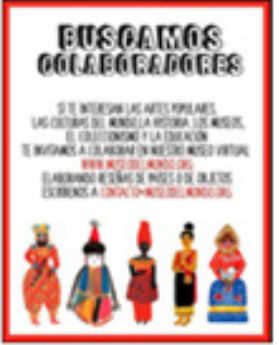

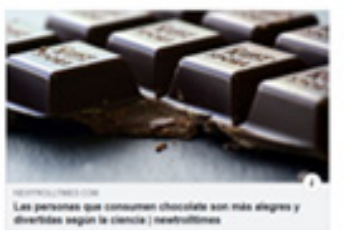

6

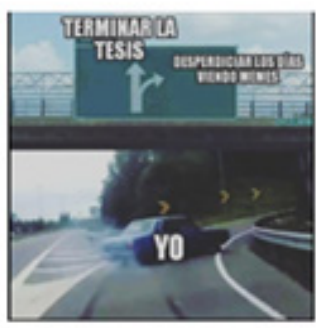

10

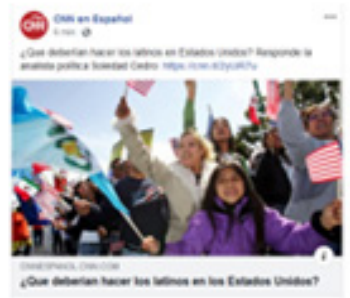

3

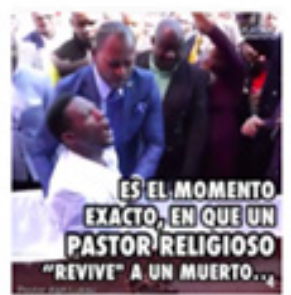

7

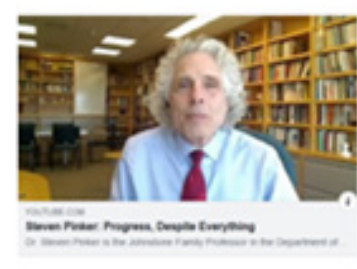

11

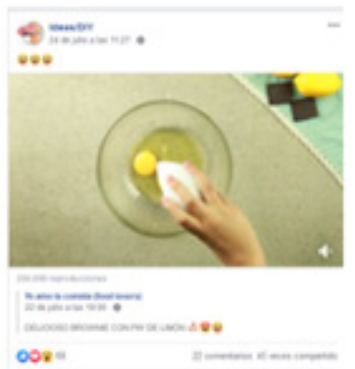

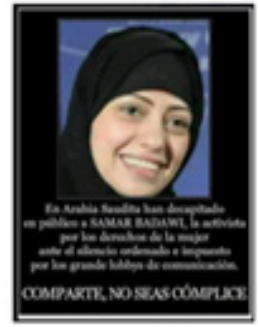

8

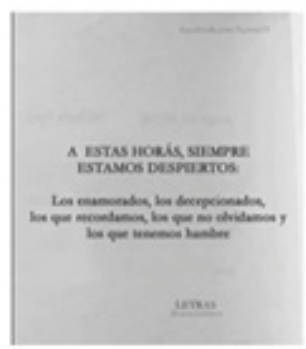

12

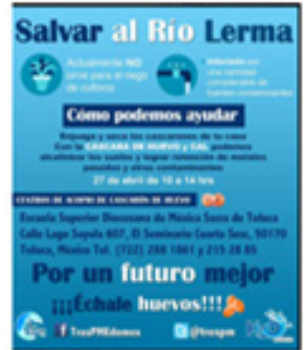

Fuente: capturas de pantalla de la plataforma Facebook.

En su conjunto, los reactivos permitieron el acercamiento a la comprensión de las literacidades críticas de los estudiantes seleccionados.

\section{Resultados}

Una vez que se descargaron las respuestas en Excel desde los formularios de Google, se analizaron las gráficas. De acuerdo con el análisis de resultados, 54\% eran estudiantes de tercer semestre, y $39 \%$ de quinto, el resto pertenecían a séptimo y octavo. Por género, $61 \%$ eran mujeres y $39 \%$ hombres. En cuanto a las preguntas asociadas a los medios de información, los participantes expresaron que el medio más idóneo para conocer noticias son las redes sociales virtuales (73\%), por su rapidez, accesibilidad y porque no tienen censura en cuanto a la infor- 
mación. La mayoría de los estudiantes indica que accede a documentos informativos (52\%) y científicos (47\%), seguidos de los humorísticos (40\%), y en menor grado a textos instructivos (11\%). El promedio de tiempo de uso de las redes es entre 2 y 3 horas diarias (31.8\%), seguidas de un promedio de 5 a 6 horas (22\%), y entre las redes que más utilizan señalan a Facebook, seguida de Instagram y WhatsApp.

Las siguientes preguntas del cuestionario están relacionadas con las categorías elegidas en la primera sección, la referente a las preguntas de opción y selección múltiple con opción a dar respuestas abiertas, lo que indica que en este caso los resultados tienen que ver más con las opiniones que con las acciones. Para presentar los resultados del análisis en la primera sección del instrumento, optamos por organizar la información en torno a las categorías ya definidas para la literacidad crítica.

1. Diálogo horizontal democrático. En la revisión de las preguntas relativas a la socialización de la información que los estudiantes ven en redes sociales, la mayoría expresa que comenta las noticias que ven en ese medio, principalmente en su círculo cercano (familia y amigos) (86\%); entre las razones para lo anterior, señalan que pueden debatir e informarse de esta manera. $79 \%$ dice que comenta noticias de redes sociales en el ámbito académico por razones similares. En cuanto a las habilidades que ellos perciben que utilizan en sus interacciones en redes sociales virtuales, están la empatía, seguida de la escucha/lectura activa, y el respeto; y las que menos utilizan son la negociación, la persuasión, el lenguaje verbal, la resolución del conflicto y la validación emocional. Respecto a los mecanismos para interactuar y compartir la información que ven en redes sociales, la mayoría afirma que lo hace a través de comentarios en redes sociales (72\%), seguido de publicar estados en redes sociales. La actividad que menos realizan respecto a la comunicación es entablar diálogos directos con representantes de gobierno.

2. Pensamiento colectivo. En el ámbito de las interacciones, los estudiantes manifestaron que se preocupaban principalmente por el ámbito mundial, seguido del nacional y finalmente el local.

3. Empoderamiento. En cuanto a la percepción de los estudiantes sobre su rol ante la información y su difusión en las redes sociales virtuales, se les dieron varias opciones: novato, explorador, consumidor de información, transmisor de información, prosumidor, líder de opinión o influencer, además de dar la opción a respuestas abiertas. La mayoría de los estudiantes se percibieron a sí mismos como exploradores (50\%), seguidos de la opción consumidor de información (41\%), lo que significa que no se ven como agentes sino como receptores de información, que no crean y no aportan a lo que se produce. Algunos más se percibieron como transmisores de información (23\%), y otros como novatos (18\%), solo $2 \%$ se consideró líder de opinión, y ninguno como prosumidor, ni 
como influencer. Esto se articula con otra pregunta que se refiere a la frecuencia con que ellos comparten la información que consumen. Este reactivo tenía la intención de conocer si ellos difunden lo que leen, y sus razones. La mayoría expresó que comparte información con frecuencia media (54\%), aunque en sus razones la mayoría de ellos externó que no les gusta compartir información a menos que sea muy necesario, en general, indican que solo leen la información, pero que no la comparten con los demás pues les parece un asunto privado.

4. Construcción propia del conocimiento. En lo respectivo a la forma en que los estudiantes se informan, se encontró que la mayoría (72\%) se informa a través de las redes sociales porque les brindan ventajas en velocidad y accesibilidad. Los contenidos que consultan más son los de corte informativo, y le siguen el científico y el humorístico, con un promedio de 2 a 3 horas diarias. La red social que utilizan más es Facebook, seguida de Instragram, y entre las que menos utilizan para informarse están Twitter y Whatsapp. Los sucesos de los que más se informan son temas culturales, seguidos de los ambientales y de género. Esto de alguna manera se contrapone a lo que ellos difunden, pues la mayoría comentó que comparten contenidos humorísticos. Respecto a los procesos que realizan una vez que revisan la información, la mayoría expresó que los analizan, la mitad de ellos los verifican y comparten, solo $13 \%$ los comentan en redes, y $2 \%$ discute la veracidad de la información con personas en su entorno.

5. Acción participativa. En cuanto a las acciones que realizan con la información para transformar la realidad, los involucrados expresaron que en general se interesan en firmar peticiones relacionadas con el medio ambiente, seguidas de aquellas relacionadas con los derechos de animales y los derechos humanos. Respecto a su participación en marchas convocadas en internet, $73 \%$ indicó que no acude, y entre las razones más frecuentes están la falta de importancia de las marchas y el desinterés por las mismas. De igual forma, los estudiantes mostraron poco interés en reactivos asociados a campañas de conscientización, juntas colectivas, plantones y pláticas con representantes gubernamentales. Sin embargo, también destaca que $73 \%$ de los estudiantes refiere como medio de acción comentar publicaciones en redes sociales virtuales, aunque evitan enviar información a manera de cadenas por esta vía. Además de esto, los comportamientos que han cambiado con base en lo que comentan, se refieren al incremento en las medidas de su seguridad y el cuidado de su privacidad.

6. Solidaridad. Respecto a las emociones que experimentan los estudiantes al leer noticias en redes sociales, la mayoría de ellos expresó que sienten curiosidad, seguida por empatía, asombro, aburrimiento y, por último, indignación.

7. Autocrítica. En cuanto a las percepciones sobre sus procesos propios, en este caso los asociados a la forma en que acceden a la información y cuidan de sí en los medios, la 
mayoría expresó que corrobora la información que lee, principalmente en documentos de investigación y páginas especializadas en la verificación de la información. Respecto a su seguridad, 54\% expresó que desconocen los mecanismos para decidir sobre la información a la que quieren acceder, por lo que sus búsquedas están determinadas por los algoritmos de las redes y buscadores que usan. En cuanto a los elementos que utilizan para decidir si la información que leen es cierta, manifiestan que revisan los datos del autor, página, fecha, fuentes, imágenes, recurrencia de la información en internet.

En la segunda sección del instrumento, donde se presentaron noticias, hubo la posibilidad de comparar tanto las percepciones a través de las respuestas como ejemplificar las acciones que llevarían a cabo en la red social, lo que también permite interpretar las formas en que los estudiantes reaccionan de manera cotidiana ante información similar en las redes sociales virtuales.

1. Para el caso de la primera noticia, asociada a un hecho real de desaparición de un estudiante menor de edad, $45 \%$ de los estudiantes indicó que no abriría la noticia y ni siquiera la leería. Entre las emociones que describen experimentaron, fue recurrente la angustia y la frustración. Este hecho se hizo visible a través de las reacciones de la red social de la siguiente forma: 16\% seleccionó la reacción 'me entristece', y 15.9\% 'me sorprende', seguida de $6.1 \%$ 'me enoja' y $6.8 \%$ 'me gusta'.

2. La segunda noticia, asociada a un hecho de violencia social acerca de un asesino serial, 52\% de los estudiantes expresó que ni siquiera leería la noticia; del 48\% restante, 79\% leería la noticia. En cuanto a las reacciones experimentadas, 29\% indicó que le sorprendía la información y le causaba enojo principalmente, seguido de miedo y $40 \%$ la compartiría en sus redes. $43 \%$ dijo que no haría nada con la información. Respecto a las reacciones, 29\% mostró que le sorprendía la información y 94\% que le enojaba.

3. Respecto a la tercera noticia, que además se informó que no era actual, $52 \%$ afirmó que no la leería, pero que la compartirían y que les causaba enojo. 18\% indicó que le enojaba; a $11 \%$ le sorprendía, y a $9 \%$ le divertía.

En la tercera sección, donde hemos descrito que se trabajó con impresiones de pantalla de 12 publicaciones variadas en las redes sociales, hubo más posibilidad de ver las acciones que los estudiantes realizan cuando ven publicaciones; esto, toda vez que se trató de emular a la red social dentro del formulario, por supuesto, con limitaciones respecto a la expansión de información, que también es un comportamiento que se puede suscitar en redes sociales. En esta sección también se mantuvo el formulario sin obligar a dar respuesta, justamente para saber qué tan interesados estaban en la información. Se encontró lo siguiente para cada una de las imágenes, de acuerdo con su número en el instrumento: 
1. Los participantes indicaron que no les fue interesante la información, $70 \%$ no la compartiría, 32\% pulsó la reacción 'me gusta'.

2. Los estudiantes pasaron por alto la noticia, aunque $18 \%$ pulsó 'me divierte', $88 \%$ no la compartiría, varios de ellos indicaron que parecía información falsa.

3. A $41 \%$ de estudiantes le pareció divertida la publicación, esto es relevante ya que la información tenía tintes religiosos y no era real. $90 \%$ no la compartiría, un número importante de participantes indicó que no era real.

4. $27 \%$ de estudiantes marcó que le causaba enojo la noticia, $34 \%$ que sí la compartiría, entre otras razones, porque les parecía un problema de interés general.

5. $27 \%$ indicó que le sorprendía la información, $22 \%$ sí la compartiría, la mitad indicó que le parecía necesario difundir, y la mitad, que dudaba de la veracidad de la información.

6. $61 \%$ indicó que le divertía la imagen, 52\% la compartiría; entre las razones indicadas estaba que precisamente les parecía graciosa la información.

7. A $36 \%$ le gustó la noticia; $36 \%$ dijo que sí la compartiría porque les parecía relevante, aunque la mayoría de ellos dijo que no comprendía la publicación.

8. $32 \%$ indicó que le divertía la imagen, $9 \%$ dijo que le encantaba, $22 \%$ la compartiría al ser un tema romántico o al expresar algo personal.

9. $31 \%$ indicó que le encantaba la noticia y $25 \%$ que le gustaba, $70 \%$ la compartiría, y la razón que daban es que a sus conocidos les podría interesar.

10. 39\% indicó que le gustaba la noticia, 52\% la compartiría; entre las razones, señalaron que tiene que ver con algo que deben conocer, algunos externaron que tenían familia en el extranjero, otros, que era parte de la conciencia crítica.

$11.27 \%$ indicó que le gustaba la noticia, $88 \%$ no la compartiría, la mayoría indicó que le parecía irrelevante.

12. A 23\% de estudiantes le gustó la noticia, a 18\% le encantó; a 18\% le sorprendió; fue la noticia con mayor interacción. 63\% la compartiría; la razón fue la colaboración.

\section{Conclusiones}

Los resultados previos, permiten establecer algunas conclusiones en torno al grupo de estudiantes a quienes se les aplicó el cuestionario dentro de la facultad descrita. La primera es que las tres secciones del instrumento ayudaron a diferenciar percepciones de los comportamientos lectores y acciones en contextos emulados, que en algunos casos parecieron contrapuestos, por ejemplo, en el consumo de información. El tipo de información al que acceden los estudiantes en las redes sociales es variado; en su mayoría, los participantes mostraron indiferencia hacia la información. Pese a que dijeron consumir documentos científicos e informativos en la primera sección, se percibió interés solo en documentos de corte humorístico en la tercera sección, no obstante que los estudiantes consideran que el mejor medio de comunicación actual 
son las redes sociales y que no utilizan otros medios para informarse. Los estudiantes revisaron la información en el cuestionario de forma muy somera y, aunque en todos los casos había posibilidad de comentar sus razones para verla o no verla, en muchas ocasiones no se cuestionó la información. En las secciones donde se pregunta sobre los procesos que seguían para evaluar la información, ellos manifestaron que revisaban fuentes, pero en la sección 2 y 3 manifestaron reacciones sin cuestionar nada. Los tiempos de respuesta en el cuestionario coinciden con esta observación.

Por otra parte, se puede ver un énfasis respecto a uno de los procesos de la literacidad crítica, y es que el instrumento reflejó principalmente comportamientos lectores, aunque no hay que desestimar que el uso de reacciones y el compartir o no información, tiene que ver con la escritura desde la definición dada, pues implica la participación democrática en contextos digitales. Asimismo, de forma reiterada se vieron comportamientos de indiferencia en los participantes, la mayoría parecía espectador renuente a colaborar, y esto se corroboró en las secciones 2 y 3 , donde es posible que los estudiantes adoptaran conductas como el 'scrolling down' (desplazamiento rápido a través de la pantalla) y el 'skipping' (comportamiento para saltar la información que parece irrelevante en los primeros segundos en que aparece).

Otra de las conclusiones es que los estudiantes tienen procesos lectores en los que no emiten juicios críticos sobre lo que leen. Por otra parte, de acuerdo con las respuestas de la primera sección y las reacciones en la segunda, se observa que los estudiantes no usan la escritura como herramienta participativa y democrática en el mundo, al menos en el digital, por lo que es posible que no se vislumbren como agentes de cambio social a partir de lo que leen, pese a que reconocen que las redes sociales virtuales pueden jugar un papel determinante en la transformación de la sociedad. Con base en esto, se aprecia que la mayoría de los estudiantes tienen una percepción mínima de empoderamiento, y se preocupan poco por planificar y evaluar sus procesos lectores en las redes sociales virtuales. Respecto a esto, los procesos de comunicación de los estudiantes son horizontales, ya que pueden compartir publicaciones para informar, particularmente en ámbitos que les son cercanos, lo que se relaciona con procesos de escritura solidaria y refuerza el hecho de que no hay intereses de manipulación ya que ninguno expresó la posibilidad de persuadir, aunque algunos sí estarían dispuestos a participar en la movilización de otras personas a través de las peticiones.

La mayoría de los estudiantes se mostraron como entes pasivos, particularmente ante temas sensibles en la sociedad, como en las noticias 1 y 2 de la sección 2 , donde además experimentan ira, indignación y angustia; sin embargo, no se movilizan más que a través de la firma de peticiones o compartiendo información en sus cuentas personales. Cabe mencionar que los estudiantes no muestran reacciones en las redes sociales virtuales cuando las noticias les son sensibles, ya que ellos indicaron su sentir de forma escrita, pero no seleccionaron las reacciones de la red social. Las reacciones más recurrentes son "me divierte", por lo que parece ser que no 
tienen dificultades en mostrar esta emoción. Otro dato observable es que, a pesar de que los estudiantes perciben que tienen mayor interés por información del ámbito mundial, sus reacciones son mucho más orientadas hacia el ámbito local; esto se demuestra en la tercera sección. También se encontró que la lengua inglesa dificulta su acceso a la información ya que cuando se dejaron fragmentos científicos en inglés, los estudiantes no los tomaron en cuenta al no comprender la información.

Como se ve, desde los elementos propuestos para definir la literacidad crítica, se constata que los procesos de lectura y escritura son prácticas y acciones que suceden en ámbitos de interacción que incluyen a los medios digitales. De igual forma, estos ámbitos digitales dan lugar a la comunicación personal, laboral, social e incluso académica, a través de la que los estudiantes estructuran su mundo y ejercen su participación dentro de un proyecto social. El artículo deja ver la necesidad de trabajar con las literacidades críticas en los estudiantes universitarios dado que, aunque a través de la lectura reconocen los fenómenos que los rodean, carecen de herramientas explícitas para analizar, juzgar y valorar la veracidad de la información que se presenta como realidad, aunado a que esta lectura del mundo no les permite ejercer su expresividad y su identidad de forma completa; el instrumento no deja saber porqué, pero se entrevé la discrepancia entre las emociones que experimentan y las que plasman. Respecto de la escritura, los estudiantes no perciben de forma completa sus posibilidades de transformar su sociedad, o bien, no las utilizan con sentido de comunidad más allá del ámbito local.

Si bien la investigación no permite conocer otros aspectos respecto a la interacción escrita con otros internautas, a través de algunos ejes y directrices que se han propuesto en su definición, da pie para comprender algunos de los elementos de la literacidad crítica que se ha estudiado, y se suma a una de las necesidades que enfrenta la educación en general y a una necesaria adopción de un continuum en las literacidades. Podemos concluir que se perciben elementos de la literacidad crítica, sin embargo, estos elementos distan de la propuesta freireana en torno a la crítica como transformación de la realidad, que se ha adoptado en el documento como parte del análisis. Además, habiéndose afirmado que las redes sociales virtuales permiten interacciones donde se ejerce el poder y se influye en la realidad desde su comprensión, se ha visto que, para la muestra analizada, la conciencia crítica en cuanto a la evaluación de la veracidad de la información, la responsabilidad al difundirla y la autocrítica sobre lo que hacen en las redes sociales, es incipiente. Y en torno al pensamiento colectivo, se queda principalmente en el nivel de la sensibilización, por lo que se les percibe altamente solidarios y en su mayoría con un comportamiento democrático, pero carecen de una profunda arista de empoderamiento y acción social donde los estudiantes se perciban con la capacidad para transformar el entorno, sobre todo en el ámbito global, aunque para el ámbito local parecen ser mucho más susceptibles de hacerlo.

De igual manera, podemos agregar a las conclusiones que es necesario hacer explícitas las literacidades, con énfasis en la literacidad crítica, dentro de los planes de estudios donde se

Diálopos sobre Educación año 12 | número 23 | julio-diciembre 2021 | ISSN 2007-2171 
desenvuelven los estudiantes pues, como se puede observar, la mayoría de ellos se encuentran inmersos en las redes sociales virtuales $y$, al revisar el tiempo que pasan en ellas, podemos comprender que cada vez cobra más importancia la vida virtual en esos entornos y que la realidad tangible deriva de lo que sucede ahí.

\section{Referencias}

Ávila, N. (2016). Literacidad digital a través del currículum universitario: cursos, recursos y prácticas. Revista del Departamento de Letras, (5), 251-259. http://revistas.filo.uba.ar/index.php/exlibris/article/view/3024

Barton, D.; M. Hamilton (2004). La literacidad entendida como práctica social. En Zavala, V.; M. Niño Murcia; P. Ames. Escritura y sociedad. Nuevas perspectivas teóricas y etnográficas. Lima: Red para el desarrollo de las ciencias sociales del Perú, 109-132.

https://ecturayescrituraunm.files.wordpress.com/2015/02/barton-y-hamilton-la-literacidad-entendida-como-prc3a1ctica-social.pdf

Beltrán, D. (2017). Redes sociales virtuales como dispositivos mediáticos contemporáneos. Cuadernos de Lingüística Hispánica, (30), 105-123. https://doi.org/10.19053/0121053X.n30.0.6190

Benhumea, C.; J. Arriaga; J.Velasco (2020). ¿Promover el desarrollo humano en la universidad? Caso específico de la Universidad Autónoma del Estado de México y su Modelo de Innovación Curricular. Revista de la Educación Superior, 49(96). http://resu.anuies.mx/ojs/index.php/resu/article/view/1405/445

Carlino, P. (2005). Escribir, leer y aprender en la universidad: una introducción a la alfabetización académica. Buenos Aires: Fondo de Cultura Económica.

Carlino, P.; S. Martínez (coords.) (2009). La lectura y la escritura: un asunto de todos/as. Neuquén: EDUCO-Universidad Nacional del Comahue.

Cassany, D. (2007). De la alfabetización a la literacidad crítica. Rapport, 10-15. https://revistas.ucu.edu.uy/index.php/revistadixit/article/view/193

Cassany, D. (2014). Literacidad crítica: leer y escribir la ideología. Researchgate, 89-96. https:/www.researchgate.net/publication/251839730 Literacidad critica leer y escribir la ideologia/link/ 0046352ca74ca3a32c000000/download

Cassany, D.; J. Castellá (2010). Aproximación a la literacidad crítica. Perspectiva, 28(2), 253-374 https://repositori.upf.edu/bitstream/handle/10230/21187/Cassany PERSPECTIVA 28 2.pdf?sequence=1

Catts, R.; J. Lau (2008). Towards Information Literacy Indicators. París: UNESCO. http://unesdoc.unesco.org/images/0015/001587/158723e.pdf

Flecha, R. (2004). La pedagogía de la Autonomía de Freire y la educación democrática de personas adultas. Revista Interuniversitaria de Formación del Profesorado, 18(2). 27-43. https:// www.redalyc.org/pdf/274/27418203.pdf

Freire, P. (2006). Pedagogía del oprimido. México: Siglo XXI editores. 
Freire. P.; D. Macedo (2005). Literacy. Reading the Word and the World. Nottingham: Taylor \& Francis. IAB México (2019). Estudio de consumo de medios y dispositivos entre internautas mexicanos. México: Televisa Digital. https://www.iabmexico.com/estudios/estudio-de-consumo-de-medios-y-dispositivos-entre-internautas-mexicanos-2019/

IFT (2019). Uso de las TIC y actividades por Internet en México: Impacto de las características sociodemográficas de la Población.

http://www.ift.org.mx/sites/default/files/contenidogeneral/estadisticas/usodeinternetenmexico.pdf

INEGI (2019). Estadísicas a propósito del Día Mundial del Internet (17 de mayo). Datos Nacionales. Comunicado de Prensa No. 252/19, 1-8. https://www.inegi.org.mx/contenidos/saladeprensa/aproposito/2019/internet2019 Nal.pdf

Kalantzis, M.; B. Cope (2012). Literacies. China: Cambridge University Press.

Lankshear, C.; M. Knobel (2008). Nuevos alfabetismos. Su práctica cotidiana y el aprendizaje en el aula. España: Morata.

Martínez Miguélez, M. (2004). Ciencia y arte en la metodología cualitativa. México:Trillas.

Rovira, G. (2016). Activismo en red y multitudes conectadas. Comunicación y acción en la era de internet. México: Universidad Autónoma Metropolitana.

Santaella, E. (2014). Pedagogía crítica, una propuesta educativa para la transformación social. Reidocre, 3, 147-171. http://digibug.ugr.es/handle/10481/32270

Selber, S. (2004). Multiliteracies for a Digital Age. Carbondale: Southern Illinois.

Tejada, H.; A. Vargas (2006). Hacia una integración de la literacidad crítica, la literacidad funcional y la literacidad cultural. Lenguaje, (35), 197-219.

http://www.redalyc.org/pdf/3459/345938959009.pdf

UNESCO (1970). La alfabetización funcional. Cómo y por qué. UNESCO. https://unesdoc.unesco.org/ark:/48223/pf0000132679

Vargas, A. (2015). Literacidad crítica y literacidades digitales: ¿una relación necesaria? (Una aproximación a un marco teórico para la lectura crítica). Revista Folios, (42), 139-160. http:// www.redalyc.org/articulo.oa?id=345938959009

Vargas, A. (2018). Redes sociales, prácticas letradas e identidad(es): el caso de Facebook. Una aproximación al estado del arte. Háblame de TIC. Prácticas de lectura y dscritura en la Era Digital, 5, 193216. Argentina: Brujas. https://www.uv.mx/blogs/brechadigital/files/2018/04/hdt5 avf8.pdf

Yagelski, P. (2000). Literacy Matters. Writing and Reading the Social Self. Nueva York: Teacher's College Press. 